\title{
Lupus erythematosus, thyroiditis, alopecia areata and vitiligo - A multiple autoimmune syndrome type 3 case presentation
}

\author{
Alin Laurentiu Tatu', Lawrence Chukwudi Nwabudike ${ }^{2}$ \\ ${ }^{1}$ Faculty of Medicine and Pharmacy, University,Dunarea de Jos ", Galati, Romania, ${ }^{2} N$. Paulescu Institute of Diabetes, \\ Str. I.L. Caragiale, Nr. 12, Sector 2, Bucharest, Romania
}

Corresponding author: Dr. Alin Laurentiu Tatu, E-mail: dralin_tatu@yahoo.com

\begin{abstract}
The combination of at least three autoimmune diseases in the same patient has defined as multiple autoimmune syndrome (MAS). Abnormalities of T cell-mediated immunity and humoral immunity have been described previously in the literature. Aims of work were to investigate the 22 years old patient with lupus erythematosus for three years and autoimune thyroiditis for one year, regardind other possible autoimmune conditions and to establish a treatment to control the diseases. The clinical exam revealed some circular hairless patches on the beard appeared about three months ago and white depigmented disseminated areas started one month ago and the laboratory investigations were performed. The modified laboratory findings were: total IgE $530 \mathrm{UI} / \mathrm{mL}$, Anti-SSA (anti-RO) antibodies $>200 \mathrm{IU} / \mathrm{mL}$, SSB negative, Antinuclear antibodies (ANA) positive and fine speckled, Lupus anticoagulant testing positive, Antithyroid peroxidase antibodies $951 \mathrm{UI} / \mathrm{ml}$,TSH 4,7 $\mu \mathrm{UI} / \mathrm{mL}$. The diagnosis of multiple autoimmune syndrome(MAS) type 3 including Lupus erythematosus, autoimune Thyroiditis, Alopecia Areata and Vitiligo was established. Endocrine autoimmunities are associated with autoantibodies that react to specific antigens, whereas patients with collagen diseases synthesize immunoglobulins that recognize nonorgan-specific cellular targets, such as nucleoproteins and nucleic acids. Cellular autoimmunity is important in the pathogenesis MAS. The existence of one autoimmune disorder helps lead to the discovery of other autoimmune conditions.
\end{abstract}

Key words: Lupus erythematosus; Autoimune thyroiditis; Alopecia areata; Vitiligo; Multiple autoimmune syndrome type 3

\section{INTRODUCTION}

The combination of at least three autoimmune diseases in the same patient has defined as multiple autoimmune syndrome (MAS). Abnormalities of T cell-mediated immunity and humoral immunity have been described previously and the literature reports overlap syndromes in various combinations; however, the coexistence of three four or even five autoimmune diseases is extremely rare $[1,2]$. Disorders of an autoimmune nature are known to occur with increased frequency in patients with another autoimmune disease. 20 percent of patients with autoimmune diseases have a tendency to develop additional autoimmune disorders [3].
Aims of this case presentation were to investigate the 22 years old patient with Lupus erythematosus for three years and autoimune thyroiditis for one year,regardind other possible autoimmune conditions and to establish a treatment to control the diseases.

\section{CASE REPORT}

A 22 year old patient with Lupus erythematosus for three years and autoimune thyroiditis for one year was referred to our dermatology department. Some circular hairless patches on the beard appeared about three months ago and white depigmented disseminated areas started one month ago (Figs. 1 and 2). The

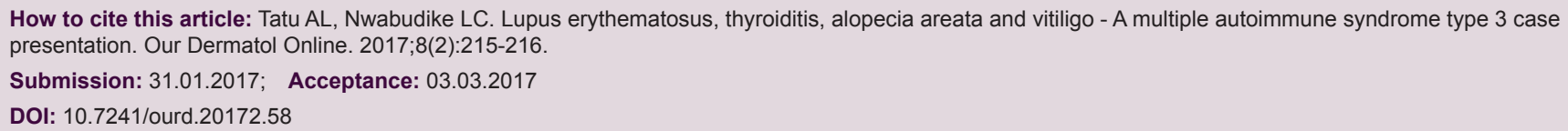




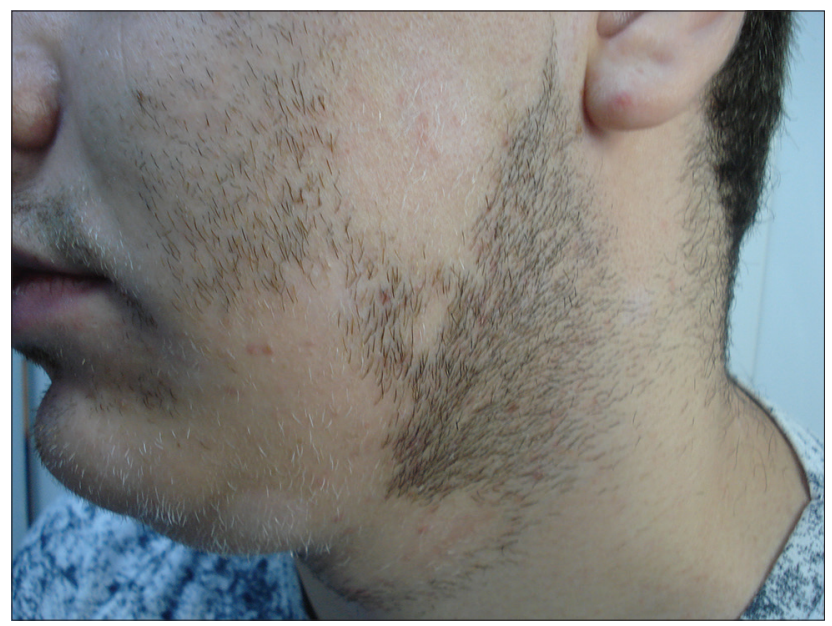

Figure 1: Alopecia Areata and Vitiligo patches on the face.

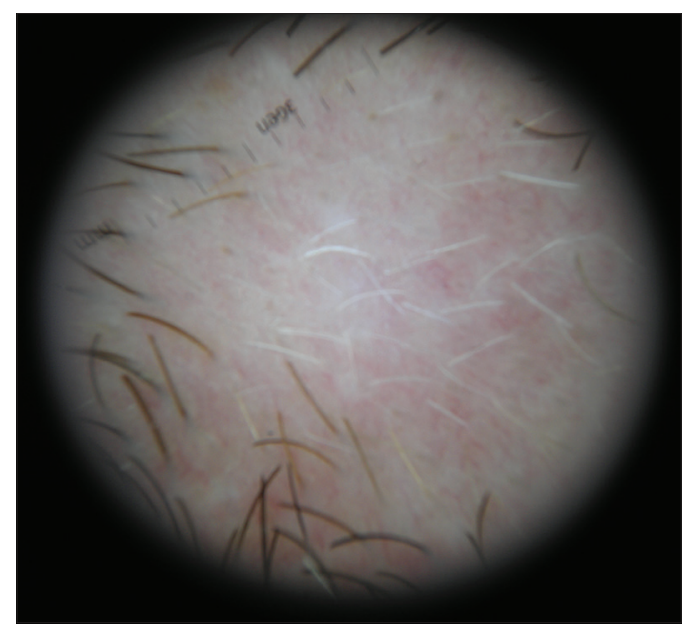

Figure 2: Dermoscopy of a patch of Alopecia Areata and Vitiligo.

modified laboratory findings were: total $\mathrm{IgE} 530 \mathrm{UI} / \mathrm{mL}$, Anti-SSA (anti-RO) antibodies> $200 \mathrm{IU} / \mathrm{mL}, \mathrm{SSB}$ negative, Antinuclear antibodies (ANA) positive and fine speckled, Lupus anticoagulant testing positive, Anti-thyroid peroxidase antibodies $951 \mathrm{UI} / \mathrm{ml}, \mathrm{TSH}$ $4,7 \mu \mathrm{UI} / \mathrm{mL}$ (one year ago TSH was $19,9 \mu \mathrm{UI} / \mathrm{mL}$ but after sodium levothyroxine $50 \mathrm{mg}$ daily decreased). The diagnosis of multiple autoimmune syndrome (MAS) type 3 including Lupus erythematosus, autoimune Thyroiditis, Alopecia Areata and Vitiligo was established [4]. Because Alopecia Areata and Vitiligo appeard despite the fact that patient was on Prednisone $30 \mathrm{mg} /$ day we reccomended a higher dose $40 \mathrm{mg} /$ day and for the dermatologic conditions-Vitiligo and Alopecia Areata, tacrolimus ointment $0,1 \%$, and a mild topical steroid-hydrocortisone butyrate $0.1 \%$ cream After 1 month the first white hairs were visible clinically and by dermoscopy but vitiligo did not improve.

\section{DISCUSSIONS}

Endocrine autoimmunities are associated with autoantibodies that react to specific antigens, whereas patients with collagen diseases synthesize immunoglobulins that recognize nonorgan-specific cellular targets, such as nucleoproteins and nucleic acids.Cellular autoimmunity is important in the pathogenesis MAS. Histologic examination of the affected tissues has demonstrated similar results, that is, mononuclear infiltrate composed mainly of lymphocytes, macrophages, natural killer (NK) cells, and plasma cells [5]. The existence of one autoimmune disorder helps lead to the discovery of other autoimmune conditions.

\section{CONCLUSIONS}

To our knowledge there are no previous citations in the medical literature about the association between Lupus erythematosus, autoimune Thyroiditis, Alopecia Areata and Vitiligo so this case presentation could be the first one reported with this conditions. Our experience is limited to this case and the challenge is to control the progression of the diseases in a team with the reumatologist and the endocrinologist regarding the corticotherapy dosage,thyroid management and combined with an efficient topical treatment.

\section{REFERENCES}

1. Tesavibul N. Multiple autoimmune diseases. The Ocular Immunology and Uveitis Foundation. Accessed March 2007.

2. Tesavibul N. Multiple autoimmune diseases. Ocular Immunology and Uveitis Foundation. Accessed January 2008.

3. Mohan MP, Ramesh TC. Multiple autoimmune syndrome. Indian J Dermatol Venerol Leprol. 2003;69:298-9.

4. Garcia-Hernandez FJ, Ocana-Medina C, Gonzalez-Leon R, GarridoRasco R, Sánchez-Román J. Autoimmune polyglandular syndrome and pulmonary arterial hypertension. Eur Respir J. 2006;27:657-8.

5. Cojocaru M, Cojocaru IA, Silosi I. Multiple autoimmune syndrome- Maedica (Buchar). 2010;5:132-4.

Copyright by Alin Laurentiu Tatu, et al. This is an open-access article distributed under the terms of the Creative Commons Attribution License, which permits unrestricted use, distribution, and reproduction in any medium, provided the original author and source are credited.

Source of Support: Nil, Conflict of Interest: None declared. 